\title{
On the Pertinence of Textbooks in Chinese as a Foreign Language
}

\author{
Huiling Sun \\ Weinan normal University, Shaanxi, China \\ Wszn30@126.com
}

\begin{abstract}
Keywords: Textbooks in Chinese as a foreign language; Principle of pertinence; Principle of need
\end{abstract}
\begin{abstract}
In many principles of compiling textbooks for foreigners, the pertinence principle is the most important, and the principle of demand is the first principle of the principle of pertinence. The other principles are to think about the problem from the point of view of the teacher. The principle of pertinence is to consider from the learner. "There is a need to have a market" Under the current theme of world peace, China cannot force any country to learn and accept our language and culture. Our teaching of Chinese as a foreign language has been built on the needs of all countries in the world. Therefore, the principle of pertinence should be put in the first place in the textbook compilation.
\end{abstract}

\section{Introduction}

The textbook compilation of Chinese as a foreign language is different from the compilation of ordinary Chinese textbooks, which should be restricted by many factors. The principle of writing has always been discussed more. At present, scholars proposed Chinese textbook compilation principles such as: pertinence principle, practical principle, scientific principle, interest-based principles, systematic principle, communication principle, knowledge principle, authenticity principle, progressive principle, the principle of diversity, modern principle, specification principle, structure-function-culture principle etc. These principles are different from each other, and the emphasis of the scholars is different too, and the understanding of each principle is also different. However, there are some general principles which are generally accepted by experts and scholars: pertinence principles, scientific principles, practical principles and interest-based principles.

\section{The Pertinence Principle Is the Most Important}

The principles of "International curriculum for Chinese language education" developed by The NOCFL ( China National Office for Teaching Chinese as a Foreign Language ) are four principles: scientific principles, practical principles, pertinence principles and universality principles. In the author's opinion, the principle of pertinence should be the most important and should be the first principle of other principles in all these principles and general principles.

\section{Why the Principle of Pertinence Is the Most Important}

In the second issue of "teaching Chinese in the world" in 2004, Mr. Li Quan's paper "on the pertinence of teaching materials for foreign Chinese" was published. In this paper, Mr. Li Quan reviewed the current situation of the research on the pertinence of the teaching materials of Chinese as a foreign language, and on this basis, it focused on three aspects: the reason and justification of teaching material pertinence; the connotation and essence of pertinence; the embodiment and implementation of the pertinence of teaching materials. Finally, the paper also discusses the relationship between the pertinence principle and other principles. More than ten years have passed, now looking back this paper, still benefited a lot, but also feel that there are some areas need to be added and emphasized.

The second part of the paper of Mr. Li Quan's is about "the connotation and essence of teaching material pertinence". In this part, Mr. Li Quan explained the connotation in detail, that is, "the design and content arrangement of teaching materials should be suitable for learners characteristics 
and needs, and should be suitable for the environment and conditions of learning; to reflect the focus and difficulty of the target language, and reflecting the nature of the subject and the characteristics of the class" These views I basically agree, but that "characteristics and needs" should be replaced position, that is to say first of all should be "suitable for the needs of learners", followed by " suitable for features of learners" The paper then talks about the specific teaching of Chinese as a foreign language. Mr. Li Quan talked about five points, of which the second points should be ranked first in order to suit learners' needs and learning needs. That is to say, "demand" should be the most important in the compilation of Chinese teaching materials for foreign languages, and it is also the first to be considered.

"There is a need to have a market", teaching Chinese as a foreign language can not violate the law of the market. Under the theme of peace in the world today, China can neither coerce nor force any country to learn to accept its own language and culture. Since our teaching of Chinese as a foreign language was originally based on the needs of all countries in the world, why did not we put it in the first place in the compilation of teaching materials? The scientific principles, practical principles and interesting principles we talked about are based on our own perspective, from the perspective of teachers. The actual needs of learners is the premise of all this. First of all, there is demand, and after the need, these principles should be considered by native language country for Chinese as a foreign language textbook. These principles do "have the same important status and role, and ignore which one is bad for improving the overall quality of the teaching materials." And "(they) contact each other and have different emphases, mutual restriction and mutual support...... It is not antagonistic, and it not one important other does not matter or a few important ones doesn't matter. "But it is true that these principles should be based on the needs of learners. If the learner does not have this need, it can't be talked about. Therefore, the demand is the first. Furthermore, the teaching materials that cannot meet the needs of the learners are also doomed to be eliminated. Therefore, focusing on the needs of the learners to write teaching materials should be the first and important. 20 years ago, Mr. Liu Xun's paper "the prospect of the new generation of teaching materials for foreigners -- and then on the compiling principles of Chinese textbooks" talked about the compiling principles of the new generation of textbooks for teaching Chinese as a foreign language. The three principles are discussed in this paper. And the second point is that the process and rules of language acquisition are well reflected in the students as the center. In this part, Mr. Liu Xun talked about "teaching service to learning", "The purpose of teaching is to learn, and teaching must be learned to produce results." "Textbooks have always been seen as teaching material, so everything starts with teaching, rarely considering the learning factor, in this sense, the compilation of teaching materials needs to change ideas and take students as the center. It is mainly embodied in the teaching materials: to understand the needs of the students and to provide the content that students want to learn the most. This makes a higher requirement for the pertinence of the teaching materials. "Therefore, the primary principle in the principle of pertinence should be the "principle of demand". Or "principle of demand" should be listed as a first principle. And "the principle of demand" is to stand on the other's position to study the problem. The first thing to consider when writing textbooks is to consider the needs of foreign learners. The second consideration is what kind of needs we can meet, what kind of needs we can't meet, and what kind of needs we can guide after meeting the legitimate needs. At the same time, we can take this as a reflection of self-examination: what kind of Chinese culture we have, and what kind of Chinese culture we need to convey, and what kind of Chinese culture we should cultivate ourselves. And all of these are things that need to be considered first, what are the needs of the learner. Considering the needs of learners, we can consider the characteristics of learners, including age, gender, identity, nationality, mother tongue, background culture, values, hobbies, learning environment, learning conditions and so on. These are all based on the learner's considerations and then, based on our consideration. That is, how to write teaching materials, adapt these characteristics with the scientific, practical, interesting and systematic principles to meet this need. In meeting the needs of learners, we also benefit ourselves, thus achieving mutual benefits. Therefore, the pertinence principle is indeed preceded by other principles and should be the most important. This is not to place a few principles on the seat, on the 
level to discuss who the first is and who the last is, such arrangement does not make any sense; it is only based on objective laws.

\section{The Way to Achieve the Principle of Pertinence}

As for the embodiment and implementation of the pertinence of the textbook, Mr. Li Quan is fully discussed in this paper. This paper not only confirms the past analysis of teaching object's age, identity, nationality, background culture, interest and hobbies, learning purpose, existing level, learning time limit and so on. It also affirmed the considerations of teaching type, class characteristics, teaching methodology and other factors, and emphasized the scientific analysis and trade-offs of these related factors. Based on this, we can find the corresponding countermeasures and specific measures, and further emphasize that we should fully and appropriately reflect these factors in the process of textbook design and compilation. What this article needs to emphasize is the understanding and demonstration of the needs. The first step in the implementation of the Pertinence is, of course, the demand argument. The demand argument cannot all be the questionnaire, but more should be the actual investigation. "I want to do more empirical research. For the teaching of Chinese as a foreign language it is a very practical subject. "As Mr. Cui Xiliang said in his speech to the fourth session of the Academic Forum on Teaching Chinese as a foreign language in the Beijing region, "So the research we have to do must be proved by data. We should really do the first hand of the research work."

But to really do the first hand of the research work, only the questionnaire is far from enough. The questionnaire itself is a complex problem. How to design a suitable problem, whether the questionnaire is distributed or not, whether the issue of the questionnaire is appropriate. What is the recovery of the questionnaire and so on, are all issues to be seriously considered. Even if all this is done well, the questionnaire does not reflect the real needs of the learner, which has been proven in countless practices. This requires local front-line teachers in a long period of teaching practice and teaching feedback to understand the needs of students. It requires not only to get along with students for a long time, but also to feel the needs of students for a long time in practical teaching, and to understand students' needs in teaching practice. It all takes time, but not just the time. And the textbook writer is best to be these long-term first-line teaching practitioners. In this way, students' needs will be fully understood and based on these principles, textbooks will be compiled. Of course, this is also a very complicated and arduous task and process. The academic circles have already discussed more and no more. This essay will not talk more about it. after the compilation of the textbook, it should be a precompiled trial, and it needs to be returned to the teaching practice to test it. It also takes time. After such practice has been practiced for some time, it will be possible to publish the official teaching materials and only after it is revised according to the problems arising in practice. And the publication of a formal textbook cannot be once and for all. Teaching materials will never catch up with teaching, and teaching material is only a summary of teaching experience. In theory, the development of teaching materials "backward" in the teaching method is normal. The teaching practice is always in the front of the textbook, but not the opposite. As for how to deal with the contradiction between teaching material and teaching practice, Lu Jianji and Mr. Yang Shiquan's paper "textbook and teaching practice" [5]have clear elaboration, which can be studied, but not in the scope of this article.

\section{Conclusion}

In a word, the first thing to consider is the pertinence in the course of writing textbook in Chinese as a foreign language. That is to say: The book is for whom. This should consider what the learner's needs are, how the learner's current language base is, and what the learner's own learning characteristics are. This kind of textbook writing is not blind, so it can play a good role in practice. But it doesn't mean that textbooks are no longer changed. In later practice teaching, we should constantly adjust and improve according to learners' actual learning situation. In order to realize the high quality teaching materials for Chinese as a foreign language, the realization of these is 
necessary for the teachers to summarize and improve constantly in the actual teaching.

\section{Acknowledgements}

The research project of the Qin Dong historical and cultural research centers（QDZD1109）

\section{References}

[1] curriculum for Chinese language education. Beijing: foreign language teaching and Research Press, 2010.

[2] Li Quan. On the pertinence of Chinese teaching materials for foreign languages, [J]. world teaching Chinese 2004, 2:49-57.

[3] Liu Xun. Prospect of a New Generation of Chinese as a Foreign Language Textbook - On Principles of Compiling Chinese Teaching Materials [J]. World Chinese teaching,1994,1: 58-67.

[4] Cui Xiliang. Speech of the Fourth Academic Forum of teaching Chinese for teaching Chinese as a foreign language in Beijing [A]. Chinese as a foreign language: Theory and practice [C]. Beijing: Beijing Language and Culture University press, 2012:1-2.

[5] Jianji Lu, Yang Shiquan. Teaching materials and teaching practice [A]. Teaching thinking set of Teaching Chinese as a foreign language [M]. Beijing: Beijing Language and Culture University press, 2005:90-97. 